\title{
Farber Disease or Lipogranulomatosis; 4 Case Reports of New Mutations in the Ceramidase Gene
}

\section{ART ICLE INF O}

\section{Article Type}

Case Report

\section{Authors}

Hadipour F. ${ }^{1} M D$

Hadipour Z. ${ }^{1} M D$,

Tavassoli A.R. ${ }^{2} M D$,

Shafaghati Y.* $M D$

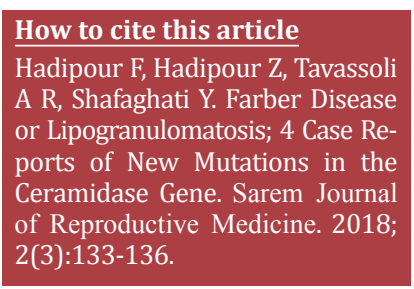

*Genetic Department, Sarem Cell Research Center (SCRC), Sarem Women's Hospital, Tehran, Iran ${ }^{1}$ Genetic Department, Sarem Cell Research Center (SCRC), Sarem Women's Hospital, Tehran, Iran

${ }^{2}$ Children's Medical Center, Medicine Faculty, Tehran University of Medical Sciences, Tehran, Iran

\section{Correspondence}

Address: Sarem Women's Hospital, Basij Square, Phase 3, Ekbatan Town, Tehran, Iran. Postal Code: 1396956111

Phone: +98 (21) 44670888

Fax: +98 (21) 44670432

dryshafagh@gmail.com

\section{Article History}

Received: March 2, 2017

Accepted: June 21, 2017

ePublished: August 15, 2018

\section{A B S T R A C T}

Patients Information Farber's lipogranulomatosis or ceramidosis is a rare lysosomal storage disease with autosomal recessive transmission. This disease is caused by the ceramidase acid deficiency, which leads to the accumulation of ceramides in the tissues. Children with a clear neuropathy die early in infancy, and those with no or negligible neurologic symptoms develop malignant deformation due to the appearance of granuloma in the joints, subcutaneous nodules, acoustic harshness and respiratory failure, and, ultimately, interstitial pneumonia; they die in the third and fourth decades.

In this study, 6 patients with Farber disease ( 5 females and 1 male) were examined in the last 7 years. In most patients, clinical symptoms included stiffness of joints and pain, weak cry, and granules around the joints. Three patients had large liver and spleen. All patients were genetically evaluated.

Conclusion We analyzed acid ceramidase gene and detected 4 novel mutations on them. Currently, 3 patients are alive.

\section{Keywords Farber Disease; Lipogranulomatosis; Acid Ceramidase; Mutation}

\section{T A T I O N L I N K S}

[1] A lipid metabolic disorder: Disseminated lipogranulomatosis; A syndrome with similarity to, and important difference from, Niemann-Pick and Hand-Schuller-Christian disease [2] Farber's disease. Report of a case with observations on its histogenesis and notes on the nature of the stored material [3] Molecular cloning and characterization of a full-length complementary DNA encoding human acid ceramidase. Identification of the first molecular lesion causing Farber disease [4] Molecular analysis of acid ceramidase deficiency in patients with Farber disease [5] Farber's disease. Light and electron microscopic study of the eye. Archives of ophthalmology (Chicago, Ill: 1960) [6] Hydrops fetalis: manifestation in lysosomal storage diseases including Farber disease [7] Molecular basis of acid ceramidase deficiency in a neonatal form of Farber disease: Identification of the first large deletion in ASAH1 gene [8] Leukocyte and plasma N-laurylsphingosine deacylase (ceramidase) in Farber disease 


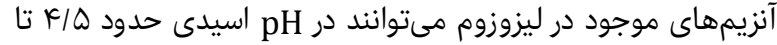

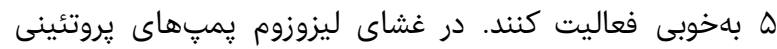

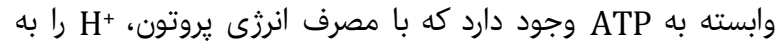

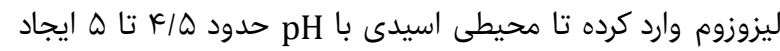

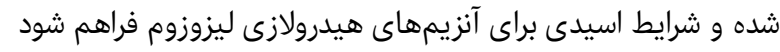

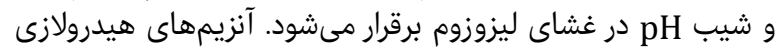

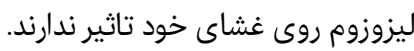

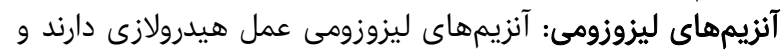

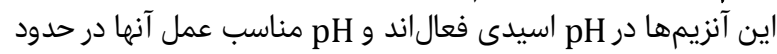

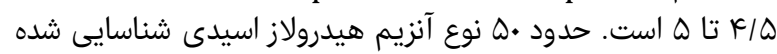

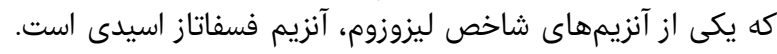

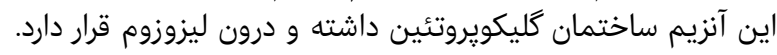

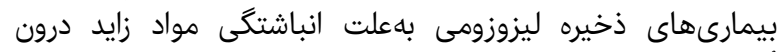

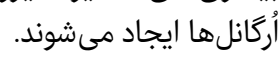

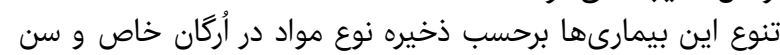

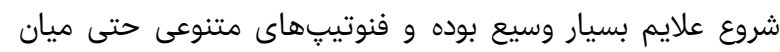

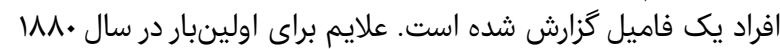

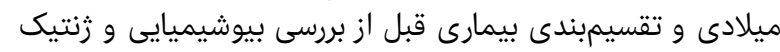

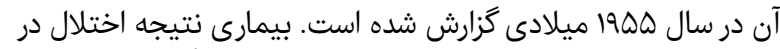

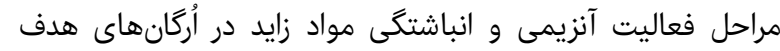

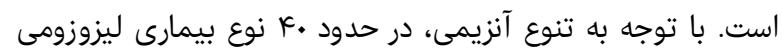

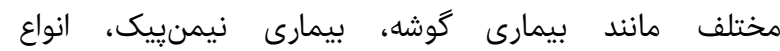

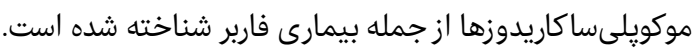

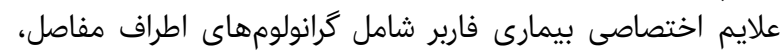

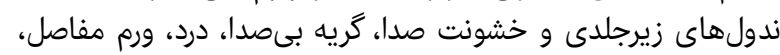

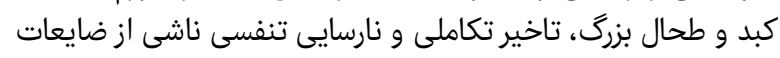

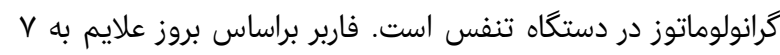
نوع زير تقسيم مى شود: نوع يك: شديد، در واقع فرم كلاسيك بيمارى و و شايعترين فرم است.

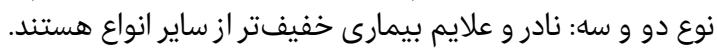

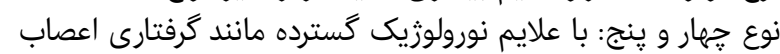
مركزى و محيطى متشنج، ميوكلونوس و تاخير تكاملى تظاهر

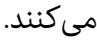
نوع شش و هفت: بسيار نادر هستند.

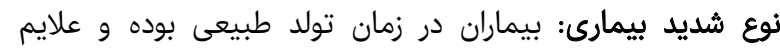

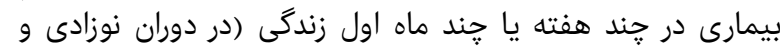

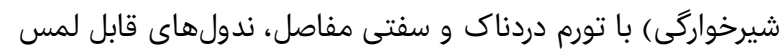

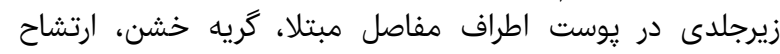

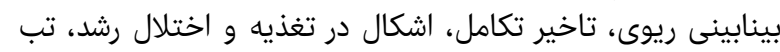

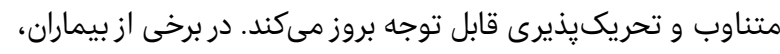

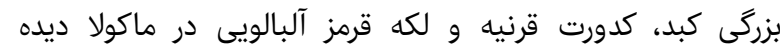

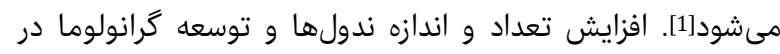

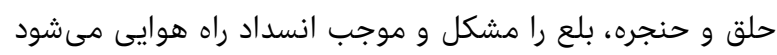

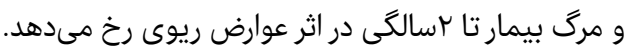

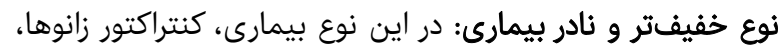

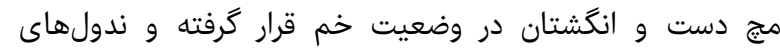

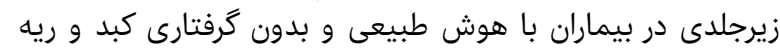

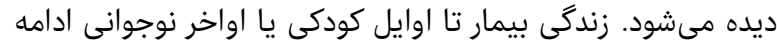

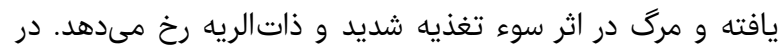

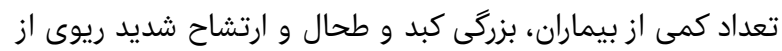
دوره نوزادى بدون وجود ندولهاى زيران زيرجلدى مشاهده مى ارثود و

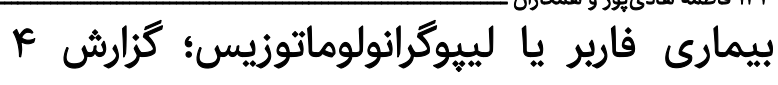
موتاسيون جديد در ثن اسيد سراميداز

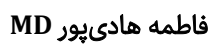

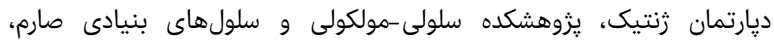
بيمارستان فوق تخصصى صارم، تهران، ايران

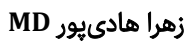

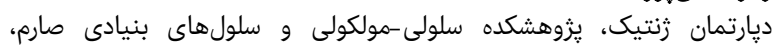
بيمارستان فوق تخصصى صارم، تهران، ايران

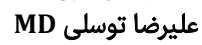

مركز طبى كودكان، دانشكده يزشكى، دانشكاه علوم بز يزشكى تهران، تهران، ايران

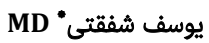

يزوهشكده سلولى-مولكولى و سلولهاى بنيادى صارم، بيمارستان فوق تخصصى صارم، تهران، ايران

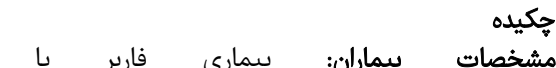

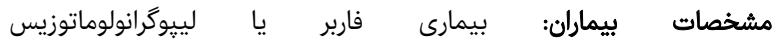

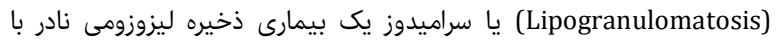

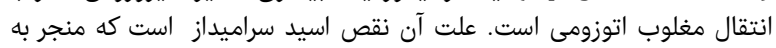

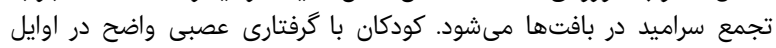

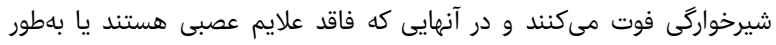

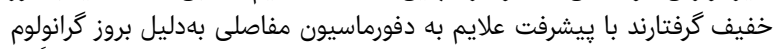

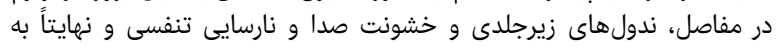

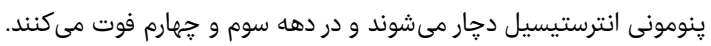

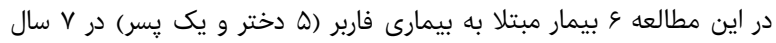

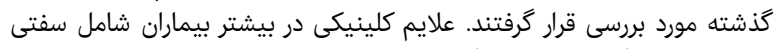

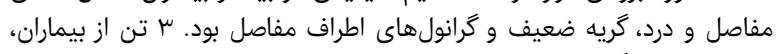

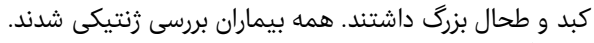

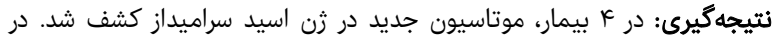

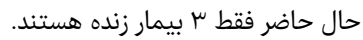

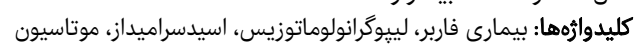

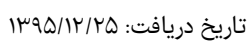

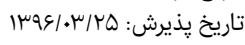

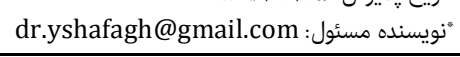

مقدمه

بيش از •ه اختلال نادر ليزوزومى شناختهشده وجود دارد كه بهطور

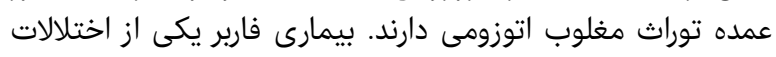

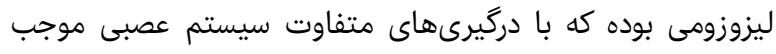

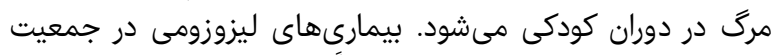

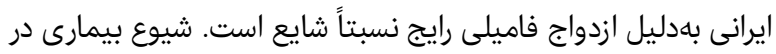

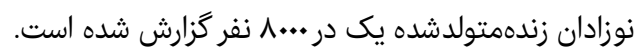

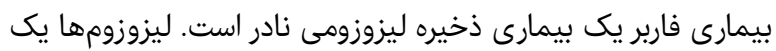

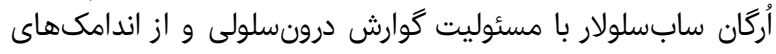

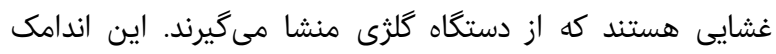

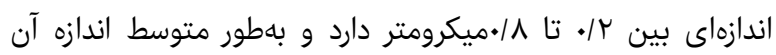

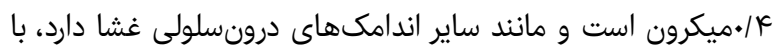

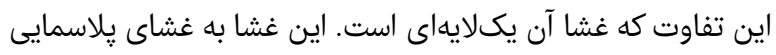

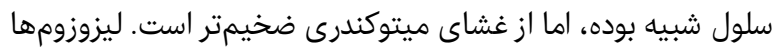

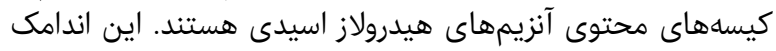

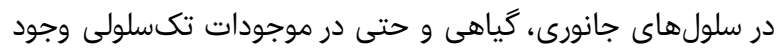

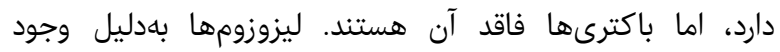

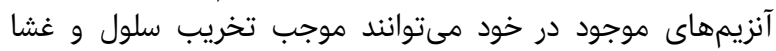

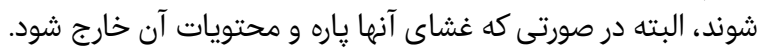




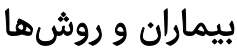
در اين گزارش 9 بيمار مبتلا به بيمارى فارشاربر يا لييوكرانولوماتوزيس

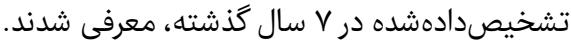

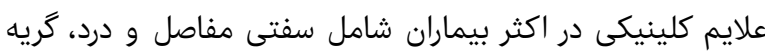

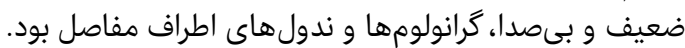

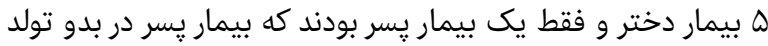

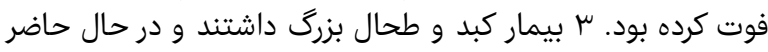

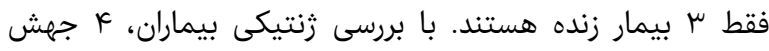

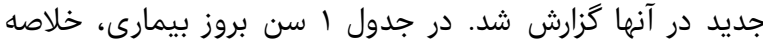

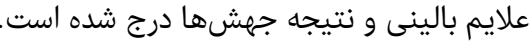
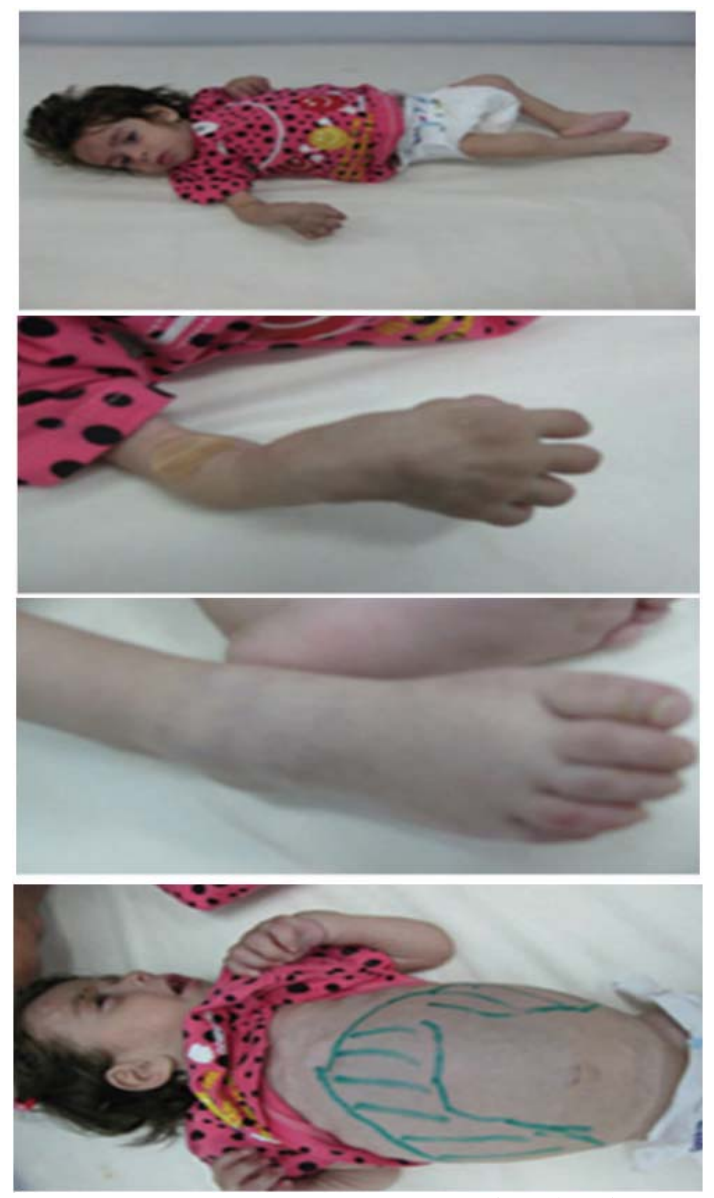

تصوير () بيمار مبتلا به فاربر
مرك در عرض קند ماه رخ مى تهدهد. نوع نادر ديكر با تاخير در تكامل،

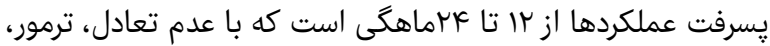

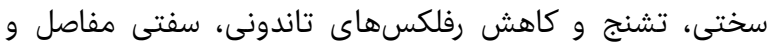

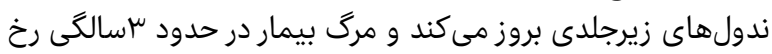

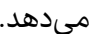

دو فرم بيمارى به شرح زير است:

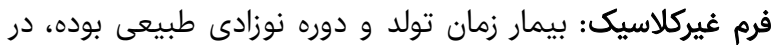

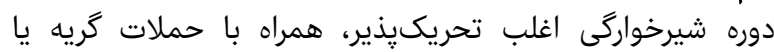

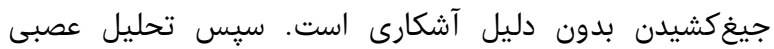

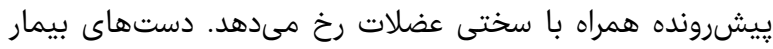

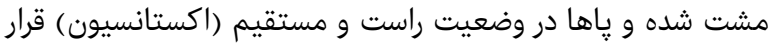

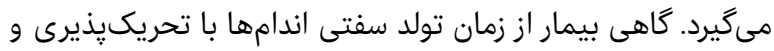

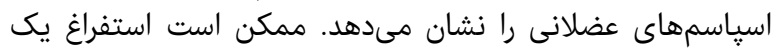

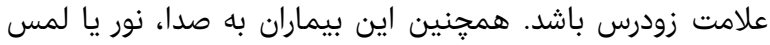

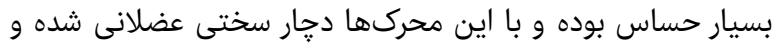

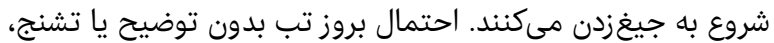

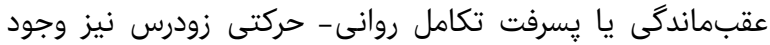

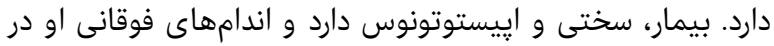

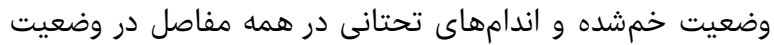

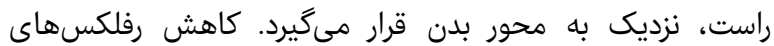

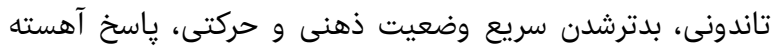

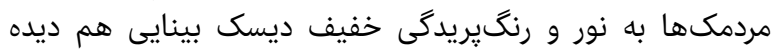

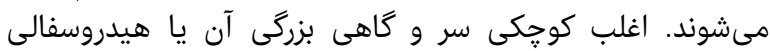

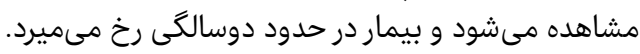

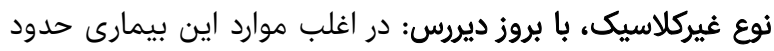

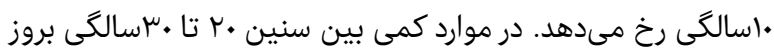

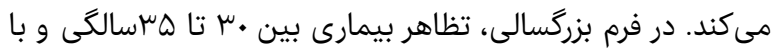

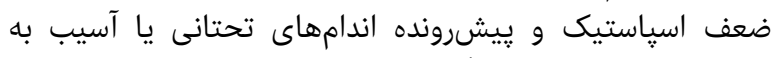
اعصاب محيطى و دمانس كزارش شئ شده است.

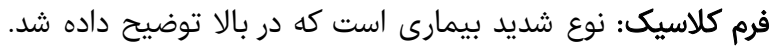

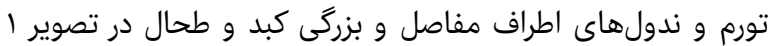

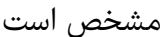

روش تشخيص: بررسى آنزيم در فيبروبلاستها، بيويسى از

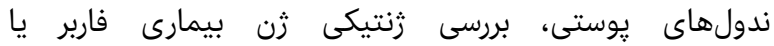

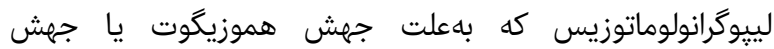
هتروزيكوت مركب در ثن كدكننده اسيدسراميداز، واقع در كروموزوم

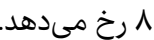

\begin{tabular}{|c|c|c|c|c|c|}
\hline جهش يافتشده در ثن ASAHI & هياتو اسيلنومگالى & تظاهرات & سن بروز & جنس & رديف \\
\hline $\begin{array}{l}\text { C. } 505 \mathrm{~T}>\mathrm{C} \\
\text { Homo }\end{array}$ & بله & التهاب، تورم و دردناكى مفاصل & 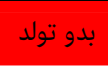 & يسر & بيمار ا \\
\hline $\begin{array}{c}\text { IVS } 09-2 \mathrm{~A}>\mathrm{G} \\
\text { Homo } \\
\text { Splice site Novel }\end{array}$ & 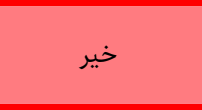 & التهاب، تورم و دردناكى مفاصل، كريه ضعيف & 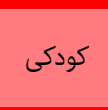 & 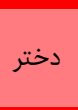 & 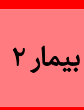 \\
\hline $\begin{array}{l}\text { C.1045C }>\mathrm{T} \\
\text { Homo } \\
\text { Ex12,Novel }\end{array}$ & فقط هياتومگالى & التهاب، تورم و دردناكى مفاصل & 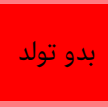 & دختر & بيمار بر \\
\hline $\begin{array}{l}\text { C. } 505 \mathrm{~T}>\mathrm{C} \\
\text { Homo }\end{array}$ & خير & التهاب، تورم و دردناكى مفاصل، كريه ضعيف & 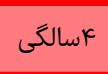 & 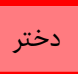 & 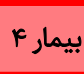 \\
\hline $\begin{array}{c}\text { c. } 553 \mathrm{~T}>\mathrm{C} \\
\text { homo } \\
\text { exon } 8, \text { NOVEL }\end{array}$ & بله & التهاب، تورم و دردناكى مفاصل، كريه ضعيف & 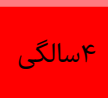 & دختر & بيماره \\
\hline $\begin{array}{c}\text { c.830C }>\mathrm{A} \\
\text { Homo } \\
\text { Exon } 10 \text { Novel }\end{array}$ & خير & التهاب، تورم و دردناكى مفاصل & كودكى & 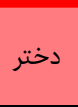 & بيمار \& \\
\hline
\end{tabular}


تشكر و قدردانى: موردى توسط نويسنده گزارش نشده است.

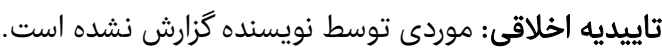

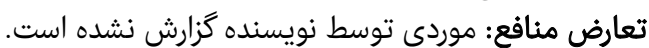

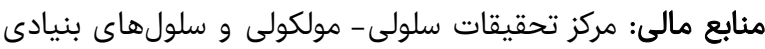

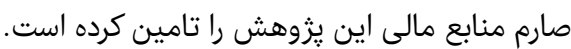

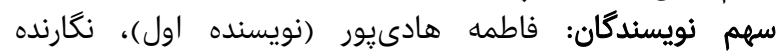

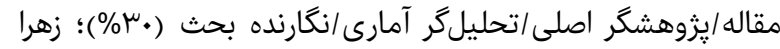

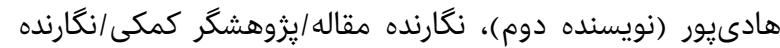

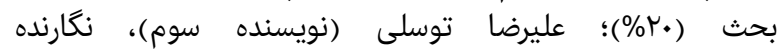

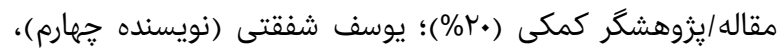

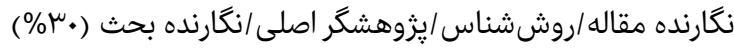

\section{منابع}

1- Farber S. A lipid metabolic disorder: Disseminated lipogranulomatosis; A syndrome with similarity to, and important difference from, Niemann-Pick and HandSchuller-Christian disease. AMA Am J Dis Child. 1952;84(4):499-500.

2- Abul-Haj SK, Martz DG, Douglas WF, Geppert LJ. Farber's disease. Report of a case with observations on its histogenesis and notes on the nature of the stored material. J Pediatr. 1962;61:221-32.

3- Koch J, Gartner S, Li CM, Quintern LE, Bernardo K, Levran O, et al. Molecular cloning and characterization of a full-length complementary DNA encoding human acid ceramidase. Identification of the first molecular lesion causing Farber disease. J Biol Chem. 1996;271(51):33110-5.

4- Bar J, Linke T, Ferlinz K, Neumann U, Schuchman EH, Sandhoff K. Molecular analysis of acid ceramidase deficiency in patients with Farber disease. Hum Mutat. 2001;17(3):199-209.

5- Zarbin MA, Green WR, Moser HW, Morton SJ. Farber's disease. Light and electron microscopic study of the eye. Archives of ophthalmology (Chicago, Ill: 1960). 1985;103(1):73-80.

6- Kattner E, Schafer A, Harzer K. Hydrops fetalis: manifestation in lysosomal storage diseases including Farber disease. Eur J pediatr. 1997;156(4):292-5.

7- Alves MQ, Le Trionnaire E, Ribeiro I, Carpentier S, Harzer K, Levade T, et al. Molecular basis of acid ceramidase deficiency in a neonatal form of Farber disease: Identification of the first large deletion in ASAH1 gene. Mol Genet Metab. 2013;109(3):276-81.

8- Ben-Yoseph Y, Gagne R, Parvathy MR, Mitchell DA, Momoi T. Leukocyte and plasma N-laurylsphingosine deacylase (ceramidase) in Farber disease. Clin Genet. 1989;36(1):38-42.
بيمارى فاربر، يك بيمارى نادر و كشنده با توارث مغلوب اتوزومى

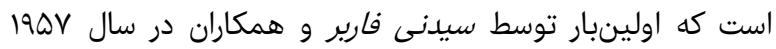

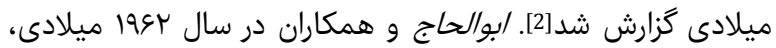

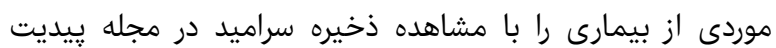

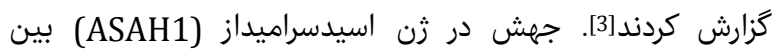

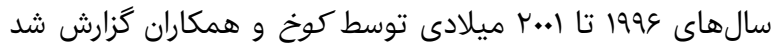

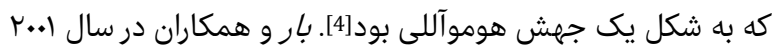

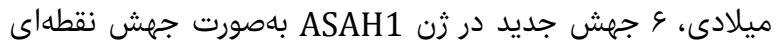

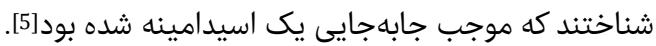

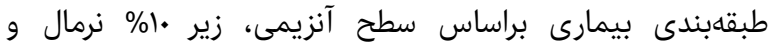

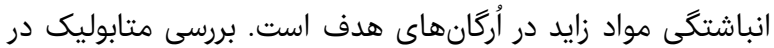

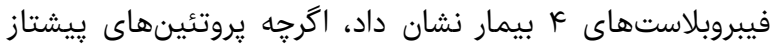

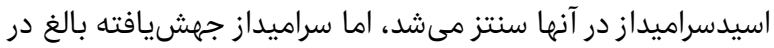

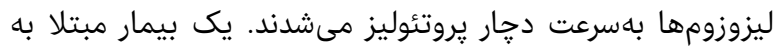

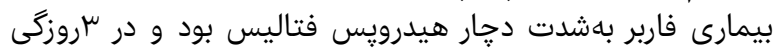

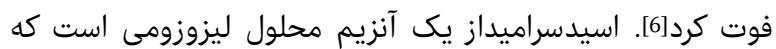

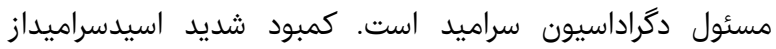

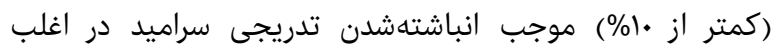

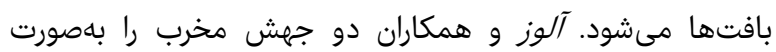

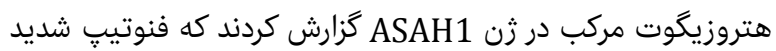

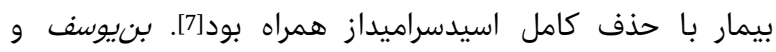

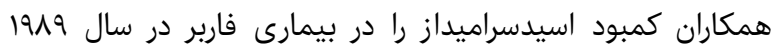

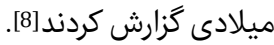

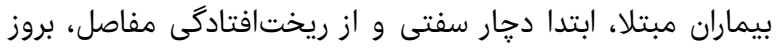

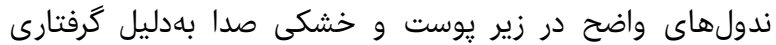

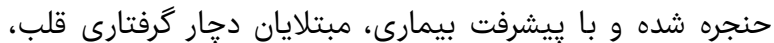

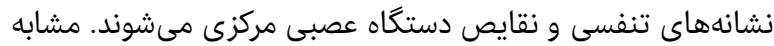

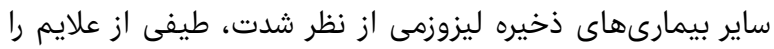
نشان مىدهند.

$$
\text { نتيجه }
$$

بيمارى فاربر يكى از بيمارىىهاى نادر ذخيره ليزوزومى است كه إنه

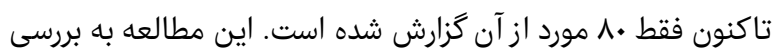

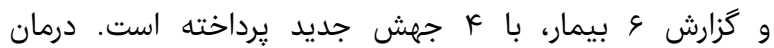

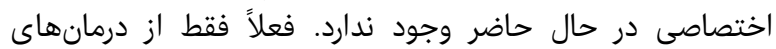

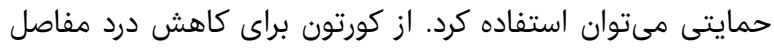

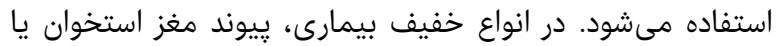

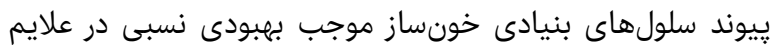

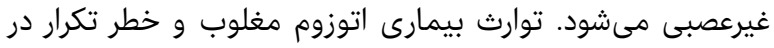

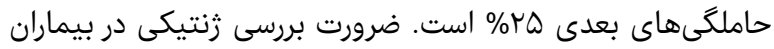

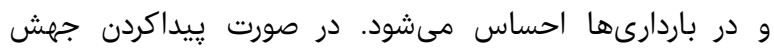
مىتوان آنها را در دوران باردارى بررسى كرد و در در صورت مبتـلابودن 